CLINICAL STUDY

\title{
Decreased serum TSH levels are not associated with mortality in the adult northeast German population
}

\author{
Till Ittermann ${ }^{1,2}$, Robin Haring ${ }^{2}$, Sybille Sauer ${ }^{1}$, Henri Wallaschofski ${ }^{2}$, Marcus Dörr ${ }^{3}$, Matthias Nauck ${ }^{2}$ \\ and Henry Völzke ${ }^{1}$ \\ ${ }^{1}$ Institute for Community Medicine, ${ }^{2}$ Institute of Clinical Chemistry and Laboratory Medicine and ${ }^{3}$ Department of Medicine, Ernst Moritz Arndt \\ University, University of Greifswald, Walther Rathenau Strasse 48, D-17487 Greifswald, Germany
}

(Correspondence should be addressed to T Ittermann at Institute for Community Medicine, Ernst Moritz Arndt University, University of Greifswald; Email: till.ittermann@uni-greifswald.de)

\begin{abstract}
Objective: Results of cohort studies on the association between decreased serum TSH levels and mortality are conflicting. Some studies demonstrated an increased mortality risk in subjects with decreased serum TSH levels, others did not. Even meta-analyses revealed contradictory results. We undertook the present study to investigate the association between decreased serum TSH levels and mortality in the large population-based Study of Health in Pomerania (SHIP).

Design and methods: Data from 3651 individuals from SHIP without known thyroid disorders or thyroid treatment were analyzed. Serum TSH, free triiodothyronine, and free thyroxine levels were determined by immunochemiluminescent procedures. Decreased TSH was defined as serum TSH levels below $0.25 \mathrm{mIU} / \mathrm{l}$. Cox regression was used to associate decreased TSH levels with mortality.

Results: The median duration of follow-up was 8.5 years (30 126 person years). During follow-up, 299 individuals $(6.9 \%)$ died corresponding to a death rate of 9.92 deaths per 1000 person years. Survival time was shorter in subjects with decreased serum TSH levels compared to euthyroid individuals. After adjustment for age and sex, however, there was no association between decreased serum TSH levels and all-cause mortality (hazard ratio: 0.95; 95\% confidence interval: 0.67; 1.36). Likewise, decreased serum TSH levels were neither associated with cardiovascular nor with cancer mortality.

Conclusions: There is no independent association of decreased serum TSH levels with all-cause, cardiovascular, and cancer mortality in the adult northeast German population. Although our study has some strengths, we cannot finally conclude on therapeutical implications in individuals with subclinical thyroid diseases.
\end{abstract}

European Journal of Endocrinology 162 579-585

\section{Introduction}

An association between decreased serum thyrotropin (TSH) levels and increased mortality may be explained by several mechanisms. Thus, decreased serum TSH levels have been reported to be associated with surrogate markers of cardiovascular mortality including carotid wall thickness (1), atrial fibrillation $(2,3)$, high plasma fibrinogen levels (4), and left ventricular hypertrophy $(5,6)$. However, results of studies on the association between decreased serum TSH levels or subclinical hyperthyroidism (3, 7-18) and mortality are conflicting. With respect to cardiovascular mortality, most studies $(3,11,12,18)$ and all meta-analyses $(10,14,17)$ detected no association between decreased serum TSH levels or hyperthyroidism and mortality, while two studies did detect an association (7, 9). Regarding all-cause mortality, one study (7) demonstrated an increased mortality risk in subjects with decreased serum TSH levels, whereas two others did not
$(12,16)$. Focusing on subclinical hyperthyroidism, four studies $(3,9,15,18)$ did not detect an association with all-cause mortality, while one study in geriatric patients (13) did. With respect to overt hyperthyroidism, one study detected a relationship to all-cause mortality (11). Different results have occurred because of nonconsideration of major confounders in some studies $(7,11,12)$, differences in definition of hyperthyroidism or follow-up time, and choice of the study population. Furthermore, some previous studies did not distinguish between subclinical and overt hyperthyroidism $(7,9,12)$. The controversy on the association between hyperthyroidism and mortality is currently fostered because even meta-analyses revealed contradictory results. While one meta-analysis demonstrated an increased mortality risk in subjects with decreased serum TSH levels (8), three others did not confirm this finding $(10,14,17)$.

With respect to cancer mortality, all available studies (19-24) compared participants after radioiodine treatment with a healthy reference group. Among these 
studies, three detected a positive $(21,22,24)$, one an inverse (20), and two $(19,23)$ no association of hyperthyroidism with cancer mortality.

In summary, current evidence for an association of decreased serum TSH levels with increased mortality is weak and nonconsistent $(10,14,17)$. Thus, we investigated the association between decreased serum TSH levels and mortality in the large population-based Study of Health in Pomerania (SHIP) distinguishing between subclinical hyperthyroidism and overt hyperthyroidism.

\section{Materials and methods}

\section{Study population}

SHIP is a population-based cohort study in West Pomerania, a region in the northeast of Germany. Details on the study design have been published previously $(1,25)$. In brief, the total population of West Pomerania comprised 212157 inhabitants. As in most parts of Germany, West Pomerania is a region of former iodine deficiency. During the 1990s, improved iodine supplementation has normalized this deficiency level resulting in a median iodine excretion value of $124 \mu \mathrm{g} / \mathrm{l}(26)$. For SHIP, a sample of the population aged 20-79 years was drawn from population registries. The net sample (without migrated or deceased persons) comprised 6267 eligible subjects. SHIP finally included 4310 participants (2193 women) corresponding to a final response of $68.8 \%$ (25). Baseline examinations were conducted between 1997 and 2001. All participants gave informed written consent. The study followed the recommendations of the Declaration of Helsinki and was approved by the Ethics Committee of the University of Greifswald.

Of the 4310 subjects who participated in SHIP, 162 subjects (76 women) had missing data in any of the considered variables, 323 subjects (272 women) reported a known thyroid disorder, 70 subjects (51 women) received thyroid treatment, and 104 subjects (68 women) had serum TSH levels above $2.12 \mathrm{mIU} / \mathrm{l}$. These 659 participants (467 women) were excluded from further analysis resulting in a population of 3651 subjects (1726 women) who were available for the present analysis.

\section{Assessments}

Socio-demographic characteristics, history of smoking, known thyroid diseases, use of anti-thyroid treatment, history of myocardial infarction, stroke, and diabetes were assessed by computer-assisted personal interviews. Smokers were categorized into three categories (lifetime nonsmokers, former smokers, and current smokers). Former smokers were individuals who had smoked during their lifetime but not in the last 12 months prior to the time of examination. Height and weight were measured for the calculation of the body mass index $(\mathrm{BMI})=$ weight $(\mathrm{kg}) /$ height $^{2}\left(\mathrm{~m}^{2}\right)$. After a $5 \mathrm{~min}$ rest period, systolic and diastolic blood pressure were measured three times at the right arm of seated subjects using a digital blood pressure monitor (HEM-705CP, Omron Corporation, Tokyo, Japan) with each reading being followed by a further rest period of $3 \mathrm{~min}$. The mean of the second and third measurements was calculated and used for the present analyses. Hypertension was defined as increased systolic $(\geq 140 \mathrm{mmHg}$ ), diastolic blood pressure $(\geq 90 \mathrm{mmHg})$, or use of anti-hypertensive medication.

Blood samples were taken in supine position between 0700 and $1600 \mathrm{~h}$, and were analyzed in the core laboratory of the University Hospital Greifswald. TSH, free triiodothyronine $\left(\mathrm{FT}_{3}\right)$, and free thyroxine $\left(\mathrm{FT}_{4}\right)$ levels were measured by immunochemiluminescent procedures $\left(\mathrm{FT}_{3}\right.$ LUMItest, Brahms, Berlin, Germany; TSH and $\mathrm{FT}_{4}$ LIA-mat, Byk Sangtec Diagnostica GmbH, Frankfurt, Germany). The functional sensitivity of the TSH assay was $0.03 \mathrm{mIU} / \mathrm{l}$. The reference range recently established for the SHIP region was 0.25-2.12 mIU/l (27). For determination of this reference range, all participants with a known thyroid disease, thyroid medication, goiter, inhomogeneous or hypoechogenic thyroid echo pattern, at least one thyroid nodule, or positive serum anti-thyroperoxidase (TPO) antibodies were excluded. Decreased TSH was defined using the lower reference level as cutoff. Subclinical hyperthyroidism was defined as serum $\mathrm{TSH}<0.25 \mathrm{mIU} / \mathrm{l}$ and $\mathrm{FT}_{3}$ and $\mathrm{FT}_{4}$ below the respective upper reference limit $\left(\mathrm{FT}_{3} \leq 7.0 \mathrm{pmol} / \mathrm{l}\right.$ and $\mathrm{FT}_{4}$ $\leq 18.9 \mathrm{pmol} / \mathrm{l}$ ) (27). Overt hyperthyroidism was defined as serum TSH levels $<0.25 \mathrm{mIU} / \mathrm{l}$ and $\mathrm{FT}_{3}$ or $\mathrm{FT}_{4}$ above the upper respective reference limit $\left(\mathrm{FT}_{3}>7.0 \mathrm{pmol} / \mathrm{l}\right.$ or $\left.\mathrm{FT}_{4}>18.9 \mathrm{pmol} / \mathrm{l}\right)$. For analysis regarding TSH in the reference range $(0.25-2.12 \mathrm{mIU} / \mathrm{l})$, groups were separated by quintiles. Serum cholesterol was measured enzymatically on a Hitachi 717 (Roche). Plasma fibrinogen concentrations were assayed according to Clauss (28) (Electra analyzer, Instrumentation Laboratory, Barcelona, Spain).

Information on vital status was collected at regular intervals from the time of enrolment into the study through August 31, 2007. Subjects were censored at death or loss to follow-up. The number of months between baseline examination and censoring was used as the follow-up length. The median duration of followup was 8.5 years $(25$ th, $7.8 ; 75$ th, 9.2). During the 30126 person years of follow-up, 299 participants (217 men) had died. During the 13913 person years of follow-up, 299 participants (217 men) had died. Death certificates were requested from the local health authority at the place of death, and coded by a certified nosologist according to the International Classification of Diseases, 10th revision (ICD10). Two internists (H W and $\mathrm{M} \mathrm{D}$ ) independently validated the underlying cause of death, and performed a joint reading together with a third internist $(\mathrm{H} \mathrm{V})$ in cases of disagreement. 


\section{Statistical analysis}

Data on quantitative characteristics are expressed as median and interquartile range. Data on qualitative characteristics are expressed as percent values or absolute numbers, as indicated. The study population was divided into two groups according to decreased serum TSH levels at baseline. Comparisons between groups were made using $\chi^{2}$-test (qualitative data) or Wilcoxon test (quantitative data). To assess the association between decreased serum TSH levels and mortality, we used Cox proportional hazards regression models with survival in years as dependent variable. Three different regression models were applied. The first crude, the second adjusted for age and sex, and the third additionally adjusted for smoking status, BMI, hypertension, myocardial infarction, stroke, cholesterol, diabetes, and fibrinogen. Additionally, interaction terms of decreased TSH with all covariates were added to the full model. All interactions with a value of $P<0.1$ were retained. The model assumption for the Cox proportional hazards regression models was checked by visual inspection of proportional hazard assumption and Schoenfeld residuals. Kaplan-Meier survival curves were used to illustrate the association between serum TSH levels and all-cause mortality, with differences tested by a log rank test. Hazard ratios (HR) were calculated with a 95\% confidence interval $(\mathrm{CI})$. A value of $P<0.05$ was considered statistically significant. This manuscript was written in accordance with the STROBE statement, giving guidelines for reporting results from observational studies (29). All statistical analyses were performed using SAS 9.1 (SAS Institute, Inc., Cary, NC, USA).

\section{Results}

Table 1 shows the baseline characteristics of individuals with and without decreased serum TSH levels. Of the 3651 individuals available for this analysis, 270 had decreased serum TSH levels (7.4\%). Compared to euthyroid subjects, individuals with decreased serum TSH levels were elder, and less often current smokers, but more often former smokers. Furthermore, participants with decreased serum TSH levels were more often hypertensive and overweight, reported more often a history of stroke, and had higher fibrinogen levels.

During follow-up, 299 individuals (6.9\%) died corresponding to 9.92 deaths per 1000 person years. More individuals with decreased serum TSH levels (15.98 deaths per 1000 person years) deceased than individuals with serum TSH levels within the reference range $(9.45$ deaths per 1000 person years; relative risk: 1.67; 95\% CI: 1.19, 2.33). Also, survival time was shorter in subjects with decreased serum TSH levels compared to euthyroid individuals (log rank test; $P=0.003)$. Proportional hazard assumption was met by all models.
Table 1 Baseline characteristics of individuals stratified by serum TSH levels. Data are given as numbers (percent) or median ( 25 and 75th percentile).

\begin{tabular}{|c|c|c|c|}
\hline & $\begin{array}{l}\text { Serum TSH } \\
\text { levels } \\
\geq 0.25 \mathrm{mlU} / \mathrm{I} \\
(n=3381)\end{array}$ & $\begin{array}{l}\text { Serum TSH } \\
\text { levels } \\
<\mathbf{0 . 2 5} \text { mIU/I } \\
(n=270)\end{array}$ & $P^{a}$ \\
\hline Sex (males) & 1807 (52.4\%) & $155(57.4 \%)$ & 0.111 \\
\hline Age (years) & $48.0(35.0 ; 62.0)$ & $61.0(48.0 ; 69.0)$ & $<0.001$ \\
\hline \multicolumn{4}{|l|}{ Smoking status ${ }^{\mathrm{b}}$} \\
\hline Former smokers & $1138(33.7 \%)$ & $111(41.1 \%)$ & 0.041 \\
\hline Current smokers & 947 (28.0\%) & 64 (23.7\%) & \\
\hline Hypertension & 1724 (51.0\%) & $161(59.6 \%)$ & 0.006 \\
\hline Stroke & $67(2.0 \%)$ & $15(5.6 \%)$ & $<0.001$ \\
\hline $\begin{array}{l}\text { Myocardial } \\
\text { infarction }\end{array}$ & $109(3.2 \%)$ & $12(4.4 \%)$ & 0.281 \\
\hline $\begin{array}{l}\text { Diabetes mellitus } \\
\text { type } 2\end{array}$ & $249(7.4 \%)$ & $26(9.6 \%)$ & 0.175 \\
\hline $\begin{array}{l}\text { Body mass index } \\
\left(\mathrm{kg} / \mathrm{m}^{2}\right)\end{array}$ & 26.7 (23.6; 29.9) & $27.4(24.9 ; 30.0)$ & 0.029 \\
\hline $\begin{array}{l}\text { Cholesterol } \\
\qquad(\mathrm{mmol} / \mathrm{l})\end{array}$ & $5.7(4.9 ; 6.5)$ & $5.6(4.9 ; 6.3)$ & 0.231 \\
\hline $\begin{array}{l}\text { Fibrinogen } \\
(\mathrm{mmol} / \mathrm{l})\end{array}$ & $8.3(7.3 ; 9.9)$ & $9.3(7.9 ; 10.9)$ & $<0.001$ \\
\hline $\begin{array}{l}\text { Time of blood } \\
\text { collection } \\
\text { (before } 1200 \mathrm{~h} \text { ) }\end{array}$ & 2038 (60.3\%) & $168(62.2 \%)$ & 0.530 \\
\hline
\end{tabular}

Table refers to subjects without increased serum TSH levels $>2.12 \mathrm{mIU} / \mathrm{l}$. ${ }^{a}{ }^{2}$-test (qualitative data) and Wilcoxon test (quantitative data).

${ }^{b}$ Reference lifetime nonsmokers.

Table 2 displays the association between decreased serum TSH levels and all-cause mortality. The crude model revealed a significant association between decreased serum TSH levels and all-cause mortality. This association was no longer present after adjustment for age and sex. Figure 1 shows the cumulative hazard functions for all-cause mortality by serum TSH levels adjusted for age and sex. Further adjustments for smoking habits, hypertension, stroke, myocardial infarction, diabetes mellitus type 2, BMI, cholesterol, and fibrinogen had only small effects on the results (Table 2). There were also no statistically significant independent associations between decreased serum TSH levels and all-cause mortality when increasing the TSH cutoff to $0.3 \mathrm{mIU} / \mathrm{l}(7,9)$ or $0.4 \mathrm{mIU} / \mathrm{l}(15,18)$ (Table 2). Furthermore, no association between TSH in the reference range (the group below the first quintile was defined as reference group) and mortality was detected (Table 2). Interactions of decreased serum TSH levels with hypertension, myocardial infarction, stroke, serum cholesterol levels, and BMI were sequentially added to model 3. None of these interactions attained statistical significance. Sex-stratified analyses showed no significant association between decreased serum TSH levels and mortality (men: HR, 1.00; 95\% CI, 0.66, $1.51 ; P=0.997$; women: HR, 0.72; 95\% CI, 0.34, 1.51; $P=0.384$ ) in the full-adjusted models. Also, analyses stratified by the time of blood collection (before and after $1200 \mathrm{~h}$ ) revealed no change of results. 
Table 2 Association of decreased serum TSH levels and TSH levels in the reference range with all-cause mortality.

\begin{tabular}{|c|c|c|c|c|}
\hline & & Model 1 & Model 2 & Model 3 \\
\hline Exposition $^{a}$ & $\begin{array}{l}\text { Number of deaths in } \\
\text { the exposure group }\end{array}$ & $\mathrm{HR}(95 \% \mathrm{Cl})$ & $\mathrm{HR}(95 \% \mathrm{Cl})$ & $\mathrm{HR}(95 \% \mathrm{Cl})$ \\
\hline $\begin{array}{l}\mathrm{TSH}<0.25 \mathrm{mlU} / \mathrm{l}(n=270) \\
\mathrm{TSH}<0.3 \mathrm{mlU} / \mathrm{l}(n=396) \\
\mathrm{TSH}<0.4 \mathrm{mIU} / \mathrm{l}(n=727) \\
\mathrm{TSH} \leq 0.03 \mathrm{mlU} / \mathrm{l}(n=15) \\
0.03 \mathrm{mIU} / \mathrm{I}<\mathrm{TSH}<0.25 \mathrm{mIU} / \mathrm{l}(n=255)\end{array}$ & $\begin{array}{r}35 \\
49 \\
81 \\
2 \\
33\end{array}$ & $\begin{array}{l}1.69(1.19 ; 2.40)^{\dagger} \\
1.63(1.20 ; 2.21)^{\dagger} \\
1.50(1.17 ; 1.94)^{\dagger} \\
0.94(0.23 ; 3.79) \\
1.76(1.23 ; 2.51)^{\dagger}\end{array}$ & $\begin{array}{l}0.95(0.67 ; 1.36) \\
0.92(0.67 ; 1.25) \\
0.91(0.71 ; 1.18) \\
0.97(0.24 ; 3.90) \\
0.96(0.67 ; 1.38)\end{array}$ & $\begin{array}{l}0.93(0.65 ; 1.33) \\
0.93(0.68 ; 1.27) \\
0.93(0.72 ; 1.20) \\
1.06(0.26 ; 4.30) \\
0.93(0.65 ; 1.34)\end{array}$ \\
\hline $\begin{array}{l}\text { TSH in the reference range } \\
0.45 \mathrm{mlU} / \mathrm{l}<\mathrm{TSH} \leq 0.61 \mathrm{mIU} / \mathrm{I}(n=673) \\
0.61 \mathrm{mIU} / \mathrm{l}<\mathrm{TSH} \leq 0.78 \mathrm{mIU} / \mathrm{l}(n=662) \\
0.78 \mathrm{mIU} / \mathrm{l}<\mathrm{TSH} \leq 1.05 \mathrm{mlU} / \mathrm{I}(n=681) \\
1.05 \mathrm{mIU} / \mathrm{I}<\mathrm{TSH}(n=666)\end{array}$ & $\begin{array}{l}52 \\
49 \\
44 \\
45\end{array}$ & $\begin{array}{l}0.72(0.51 ; 1.03) \\
0.69(0.48 ; 0.99)^{\star} \\
0.60(0.42 ; 0.88)^{\dagger} \\
0.64(0.44 ; 0.93)^{\star}\end{array}$ & $\begin{array}{l}0.93(0.65 ; 1.32) \\
0.99(0.69 ; 1.42) \\
1.06(0.73 ; 1.54) \\
1.26(0.87 ; 1.82)\end{array}$ & $\begin{array}{l}0.91(0.64 ; 1.30) \\
0.93(0.65 ; 1.33) \\
1.09(0.75 ; 1.58) \\
1.21(0.83 ; 1.76)\end{array}$ \\
\hline
\end{tabular}

${ }^{\star} P<0.05,{ }^{\dagger} P<0.01$. HR, hazard ratio; $\mathrm{Cl}, 95 \%$ confidence interval; model 1 , unadjusted Cox regression; model 2 , Cox regression adjusted for age and sex; model 3, Cox regression adjusted for age, sex, smoking status, hypertension, stroke, myocardial infarction, diabetes mellitus type 2, body mass index, cholesterol, and fibrinogen.

aReference group: euthyroid individuals above the respective cutoff; for analysis regarding the TSH reference range $(0.25 \mathrm{mIU} / \mathrm{l} ; 2.12 \mathrm{mIU} / \mathrm{l})$, individuals $<0.45 \mathrm{mIU} / \mathrm{l}$ (first quintile of TSH in the reference range) are in the reference group.

Of the 299 deceased individuals, the cause of death was not available from 41 individuals. Of the remaining 258 decedents, 96 individuals ( 25 women; $32.1 \%$ ) died from cancer (ICD code: $\mathrm{COO}-\mathrm{C} 97$ ) and 97 individuals (29 women; 32.4\%) from cardiovascular diseases (ICD code: I10-I97). After adjustment for confounders, Cox regression revealed no significant associations of decreased serum TSH levels with cancer (HR, 1.05; 95\% CI, 0.57, 1.93; $P=0.890)$ and cardiovascular mortality (HR, 1.08; 95\% CI, 0.61, 1.91; $P=0.803$ ). When alternating the TSH cutoff to $0.3 \mathrm{mIU} / \mathrm{l}$, Cox regression models disclosed a HR of 1.05 (95\% CI, 0.67, 1.63; $P=0.846)$ for cancer and 0.82 (95\% CI, 0.52, 1.30; $P=0.394$ ) for cardiovascular mortality.

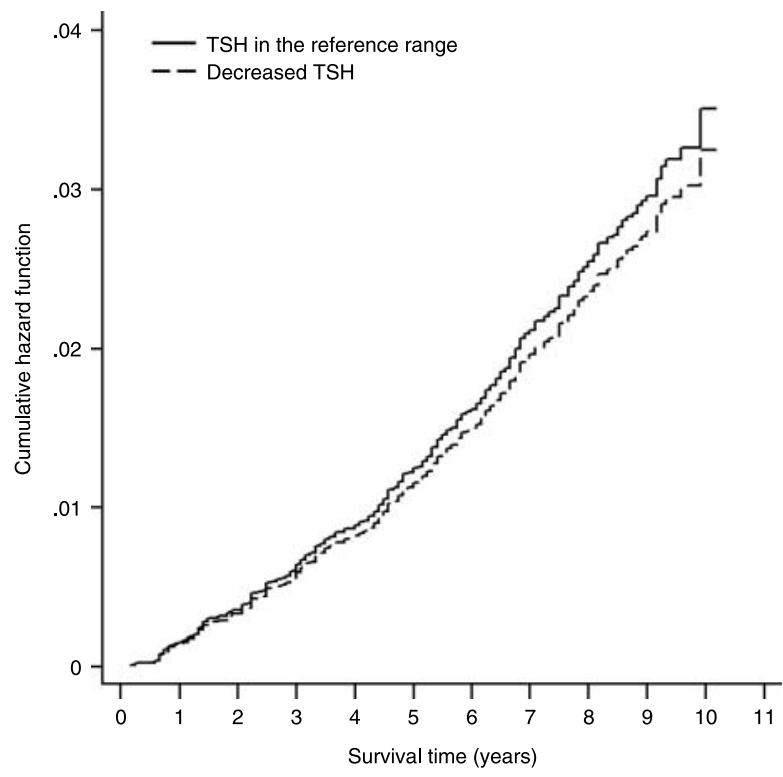

Figure 1 Cumulative hazard functions for participants with and without decreased TSH.
Finally, we divided subjects with serum TSH levels below $0.25 \mathrm{mIU} / \mathrm{l}$ into those with subclinical $(243$ subjects; 103 women) and those with overt hyperthyroidism (27 subjects; 15 women). When applying Cox regression models, there was no association of subclinical or overt hyperthyroidism with all-cause, cancer, and cardiovascular mortality (Table 3).

\section{Discussion}

In the present study, we analyzed associations of decreased serum TSH levels with all-cause, cancer, and cardiovascular mortality. We detected no such associations. Applying an alternative cutoff for decreased serum TSH levels as well as dividing individuals with decreased serum TSH levels into those with subclinical and overt hyperthyroidism did not change these results materially.

With respect to decreased serum TSH levels, our results are in line with two studies $(12,16)$. Two other studies $(7,11)$ reported an association between decreased serum TSH levels and all-cause mortality. Contrary to one study (11), we detected no relationship between overt hyperthyroidism and all-cause mortality. Focussing on subclinical hyperthyroidism, our results are in concordance with most of the previous studies (3, $9,15,18)$ and meta-analyses $(10,14)$. However, one study (13) and one meta-analysis (8) did not confirm this finding. Haentjens et al. (8) concluded that the increased likelihood of death is not immediate after the diagnosis of subclinical hyperthyroidism, but became apparent after the second year and continued up to 10 years after the diagnosis of subclinical hyperthyroidism. Haentjens et al. (8) included seven studies $(3,7,9,12$, $13,18,30)$ in their meta-analysis. Two of those $(7,12)$ did not explicitly focus on the association of subclinical hyperthyroidism with all-cause mortality, e.g. Parle et al. (12) compared participants with serum TSH levels 
Table 3 Association of subclinical and overt hyperthyroidism with all-cause, cancer, and cardiovascular mortality.

\begin{tabular}{|c|c|c|c|c|c|c|}
\hline & \multicolumn{2}{|c|}{ Model 1} & \multicolumn{2}{|c|}{ Model 2} & \multicolumn{2}{|c|}{ Model 3} \\
\hline & $\begin{array}{c}\text { Subclinical } \\
\text { hyperthyroidism } \\
(n=243 ; 31 \\
\text { deaths })\end{array}$ & $\begin{array}{c}\text { Overt } \\
\text { hyperthyroidism } \\
(n=27 ; 4 \\
\text { deaths })\end{array}$ & $\begin{array}{c}\text { Subclinical } \\
\text { hyperthyroidism } \\
(n=243 ; 31 \\
\text { deaths })\end{array}$ & $\begin{array}{c}\text { Overt } \\
\text { hyperthyroidism } \\
(n=27 ; 4 \\
\text { deaths })\end{array}$ & $\begin{array}{c}\text { Subclinical } \\
\text { hyperthyroidism } \\
\text { ( } n=243 ; \\
31 \text { deaths })\end{array}$ & $\begin{array}{c}\text { Overt } \\
\text { hyperthyroidism } \\
(n=27 ; 4 \\
\text { deaths })\end{array}$ \\
\hline & \multicolumn{2}{|c|}{$\mathrm{HR}(95 \% \mathrm{Cl})$} & \multicolumn{2}{|c|}{$\mathrm{HR}(95 \% \mathrm{Cl})$} & \multicolumn{2}{|c|}{$\mathrm{HR}(95 \% \mathrm{Cl})$} \\
\hline All-cause mortality & $1.66(1.14 ; 2.41)^{\star}$ & $1.98(0.74 ; 5.31)$ & $0.94(0.65 ; 1.37)$ & $1.01(0.38 ; 2.70)$ & $0.91(0.63 ; 1.33)$ & $1.08(0.40 ; 2.96)$ \\
\hline Cancer mortality & $1.91(1.02 ; 3.57)^{*}$ & $1.61(0.22 ; 11.57)$ & $1.07(0.57 ; 2.00)$ & $0.81(0.11 ; 5.85)$ & $1.05(0.56 ; 1.99)$ & $1.07(0.15 ; 7.82)$ \\
\hline Cardiovascular mortality & $1.92(1.03 ; 3.61)^{*}$ & $4.57(1.44 ; 14.44)^{*}$ & $0.95(0.50 ; 1.78)$ & $2.02(0.64 ; 6.40)$ & $0.97(0.51 ; 1.83)$ & $2.07(0.63 ; 6.87)$ \\
\hline
\end{tabular}

of $\leq 0.5 \mathrm{mIU} / \mathrm{l}$ with those $>0.5 \mathrm{mIU} / \mathrm{l}$. Contrary to the meta-analysis by Ochs et al. (10), Haentjens et al. (8) considered the study by Parle et al. (12) as one which has detected a significant association between subclinical hyperthyroidism and mortality. The reason for this is that Parle et al. (12) reported estimators for five different follow-up times. For a follow-up time of 10 years, they detected no association but for follow-up times of 2, 3, 4, and 5 years. This might be one explanation for conflicting results between these metaanalyses $(8,10)$. Also, the selection of studies included might be responsible for conflicting results between these meta-analyses. Völzke et al. (17) included two studies into their meta-analyses, Singh et al. (14) included three studies, and Ochs et al. (10) included five studies. Furthermore, the meta-analysis by Haentjens et al. was the first which included studies of patients with co-morbidities $(9,13,30)$.

Furthermore, four $(7,12,13,30)$ of the seven studies included in the meta-analysis by Haentjens did not adjust their models for major confounders such as age and smoking. Particularly, smoking is an important risk factor in the pathogenesis of thyroid diseases $(31,32)$. Because smoking is also an important predictor of mortality (33), the impact of hyperthyroidism on mortality might be overestimated when smoking is not considered (17). In our analysis, a statistically significant association between decreased serum TSH levels and mortality was no longer present even after adjustment for age. Since different studies did not adjust for the same covariables, it should be decided carefully which studies to include into a meta-analysis. Conclusions from meta-analyses may be hampered, if they include original results from multivariable analyses adjusted for different sets of covariables. In our study, confounders apart from age and sex did not change the results materially, but in other populations, these confounders might play a more important role.

Apart from different nonconsideration of major confounders, there are three further factors that might be responsible for contradictory results. Firstly, different definitions of hyperthyroidism might have led to conflicting results. Usually, the cutoff for serum TSH levels varied between 0.3 (7) and $0.5 \mathrm{mIU} / \mathrm{l}(12)$. Most of these studies considered $\mathrm{FT}_{4}$ levels $(3,9,11,13$, $15,16,18)$, whether others did not $(7,12)$. Secondly, differences in follow-up time play a crucial role. In previous studies on the association between hyperthyroidism and mortality, the mean follow-up time varied between 3.7 (7) and 20 years (18). Short follow-up times in smaller studies might be problematic, since the impact of the disease on mortality might be too weak. Otherwise, analysis based on long follow-up times might underestimate the influence of the exposure on mortality for misclassification bias due to change in exposure over time. In the present study, participants were informed about their laboratory results. The awareness of thyroid diseases might have led to frequent medical monitoring and early treatment decisions, which also might have introduced bias due to change in the exposure variable. This might have resulted in an underestimation of the effect of hyperthyroidism on mortality in the present study, particularly for overt hyperthyroidism. Finally, different age structures of the selected populations might have given rise to discrepant results. Some of previous studies on the association of hyperthyroidism with mortality focused on participants older than 60 years $(3,7,12,13,15)$.

With respect to cardiovascular mortality, results from our study are in concordance with most of the previously reported studies $(3,11,12,18)$ and metaanalyses $(10,14,17)$. Two other studies $(7,9)$ detected an association between decreased serum TSH levels and cardiovascular mortality. Although Iervasi et al. (9) detected no association between mild hyperthyroidism with all-cause mortality, they demonstrated that mild hyperthyroidism is an independent risk factor for cardiovascular mortality in their study. Results from this study (9) are not comparable to those from our study because they investigated this association in a subgroup of cardiac patients. While the association between decreased serum TSH levels and cardiovascular mortality is conflicting, the association between decreased serum TSH levels and nonfatal events 
including atrial fibrillation (3), high plasma fibrinogen levels (4), and left ventricular hypertrophy (6) is well established. Parts of this discrepancy might be explained by the fact that atrial fibrillation per se is at least not tightly related to increased mortality (34). Furthermore, one might assume that patients having subclinical hyperthyroidism diagnosed at the time of a cardiovascular event might be treated for the thyroid disorder or referred to a more intense clinical follow-up.

In concordance with two studies $(19,23)$, we detected no association between hyperthyroidism and cancer mortality, while three studies (20-22, 24) demonstrated such an association. However, these studies did not use population-based samples (19-24), but were conducted in patient cohorts undergoing radioiodine treatment. It is the objective of current research to answer the question whether increased mortality in these patients might be related to the exposure of ionizing radiation. Selection bias might represent an alternative explanation for the increased mortality in radioiodine patients. At least in some regions only, those patients undergo radioiodine treatments that have contraindications against surgery, i.e. elder patients with co-morbidities. Thus, increased mortality in these patients might be related to age and poor general condition rather than to thyroid dysfunction or radioiodine application.

The size of the study population represents a major limitation of the present study. Although in the present study risk estimators were mostly close to 1 , a weak association between decreased serum TSH levels and all-cause mortality with an HR of $<1.65$ might have been missed from detection due to power reasons. In particular, the number of subjects who were classified as overt hyperthyroid and those who died from cancer and cardiovascular diseases was too low. Therefore, further research is strongly needed in that respect. Another limitation of our study is the less well-standardized time of blood specimen collection. It has been previously reported that serum TSH levels might alter by daytime (35). Therefore, we performed analyses stratified by the time of blood sampling, which did not change the results materially. Strengths of our study include the population-based approach and the definition of thyroid dysfunction using not only TSH but also free thyroid hormones.

In conclusion, we detected no independent association of decreased serum TSH levels with all-cause, cancer, and cardiovascular mortality in the adult northeast population of Germany. Although our study has some strengths, we cannot finally conclude on therapeutical implication to treat or not to treat individuals with subclinical thyroid diseases.

\section{Declaration of interest}

The authors declare that there is no conflict of interest that could be perceived as prejudicing the impartiality of the research reported.

\section{Funding}

The work is part of the Community Medicine Research net (CMR) of the University of Greifswald, Germany, which is funded by the Federal Ministry of Education and Research (grant no. ZZ9603), the Ministry of Cultural Affairs, as well as the Social Ministry of the Federal State of Mecklenburg-West Pomerania. The CMR encompasses several research projects that are sharing data of the population-based SHIP (http://www.medizin.uni-greifswald.de/icm/). Analyses were further supported by a grant of the German Research Foundation (DFG Vo 955/5-1). This research work was funded by grants from the German Federal Ministry for Education and Research, from the Ministry for Education, Research and Cultural Affairs, the Ministry for Social Affairs of the State Mecklenburg-West Pomerania and the DFG.

\section{References}

1 Volzke H, Robinson DM, Schminke U, Ludemann J, Rettig R, Felix SB, Kessler C, John U \& Meng W. Thyroid function and carotid wall thickness. Journal of Clinical Endocrinology and Metabolism 200489 2145-2149.

2 Auer J, Scheibner P, Mische T, Langsteger W, Eber O \& Eber B. Subclinical hyperthyroidism as a risk factor for atrial fibrillation. American Heart Journal 2001142 838-842.

3 Cappola AR, Fried LP, Arnold AM, Danese MD, Kuller LH, Burke GL, Tracy RP \& Ladenson PW. Thyroid status, cardiovascular risk, and mortality in older adults. Journal of the American Medical Association 2006295 1033-1041.

4 Dorr M, Robinson DM, Wallaschofski H, Schwahn C, John U, Felix SB \& Volzke H. Low serum thyrotropin is associated with high plasma fibrinogen. Journal of Clinical Endocrinology and Metabolism 200691 530-534.

5 Biondi B, Palmieri EA, Fazio S, Cosco C, Nocera M, Sacca L, Filetti S, Lombardi G \& Perticone F. Endogenous subclinical hyperthyroidism affects quality of life and cardiac morphology and function in young and middle-aged patients. Journal of Clinical Endocrinology and Metabolism 200085 4701-4705.

6 Dorr M, Wolff B, Robinson DM, John U, Ludemann J, Meng W, Felix SB \& Volzke H. The association of thyroid function with cardiac mass and left ventricular hypertrophy. Journal of Clinical Endocrinology and Metabolism 200590 673-677.

7 Gussekloo J, van Exel E, de Craen AJ, Meinders AE, Frolich M \& Westendorp RG. Thyroid status, disability and cognitive function, and survival in old age. Journal of the American Medical Association $20042922591-2599$.

8 Haentjens P, Van Meerhaeghe A, Poppe K \& Velkeniers B. Subclinical thyroid dysfunction and mortality: an estimate of relative and absolute excess all-cause mortality based on time-to-event data from cohort studies. European Journal of Endocrinology 2008159 343-345.

9 Iervasi G, Molinaro S, Landi P, Taddei MC, Galli E, Mariani F, L'Abbate A \& Pingitore A. Association between increased mortality and mild thyroid dysfunction in cardiac patients. Archives of Internal Medicine 2007 167 1526-1532.

10 Ochs N, Auer R, Bauer DC, Nanchen D, Gussekloo J, Cornuz J \& Rodondi N. Meta-analysis: subclinical thyroid dysfunction and the risk for coronary heart disease and mortality. Annals of Internal Medicine $2008 \mathbf{1 4 8} 832-845$.

11 Osman F, Franklyn JA, Holder RL, Sheppard MC \& Gammage MD. Cardiovascular manifestations of hyperthyroidism before and after antithyroid therapy: a matched case-control study. Journal of the American College of Cardiology 200749 71-81.

12 Parle JV, Maisonneuve P, Sheppard MC, Boyle P \& Franklyn JA. Prediction of all-cause and cardiovascular mortality in elderly people from one low serum thyrotropin result: a 10-year cohort study. Lancet 2001358 861-865. 
13 Radacsi A, Kovacs G, Bernard W, Feldkamp J, Horster FA \& Szabolcs I. Mortality rate of chronically ill geriatric patients with subnormal serum thyrotropin concentration: a 2-yr followup study. Endocrine 200321 133-136.

14 Singh S, Duggal J, Molnar J, Maldonado F, Barsano CP \& Arora R. Impact of subclinical thyroid disorders on coronary heart disease, cardiovascular and all-cause mortality: a meta-analysis. International Journal of Cardiology 2008125 41-48.

15 van den Beld AW, Visser TJ, Feelders RA, Grobbee DE \& Lamberts SW. Thyroid hormone concentrations, disease, physical function, and mortality in elderly men. Journal of Clinical Endocrinology and Metabolism 200590 6403-6409.

16 Volzke H, Menzel D, Henzler J, Robinson D, Motz W, Rettig R \& Dorr M. Serum thyrotropin levels predict all-cause and circulatory mortality in patients with invasively treated coronary artery disease. International Journal of Cardiology 2008133 407-410.

17 Volzke H, Schwahn C, Wallaschofski H \& Dorr M. Review: the association of thyroid dysfunction with all-cause and circulatory mortality: is there a causal relationship? Journal of Clinical Endocrinology and Metabolism 200792 2421-2429.

18 Walsh JP, Bremner AP, Bulsara MK, O’Leary P, Leedman PJ, Feddema P \& Michelangeli V. Subclinical thyroid dysfunction as a risk factor for cardiovascular disease. Archives of Internal Medicine $20051652467-2472$.

19 Flynn RW, Macdonald TM, Jung RT, Morris AD \& Leese GP Mortality and vascular outcomes in patients treated for thyroid dysfunction. Journal of Clinical Endocrinology and Metabolism 2006 $912159-2164$.

20 Franklyn JA, Maisonneuve P, Sheppard M, Betteridge J \& Boyle P. Cancer incidence and mortality after radioiodine treatment for hyperthyroidism: a population-based cohort study. Lancet 1999 353 2111-2115.

21 Goldman MB, Monson RR \& Maloof F. Cancer mortality in women with thyroid disease. Cancer Research 199050 2283-2289.

22 Hall P, Berg G, Bjelkengren G, Boice JD Jr, Ericsson UB, Hallquist A, Lidberg M, Lundell G, Tennvall J, Wiklund K \& Holm LE. Cancer mortality after iodine-131 therapy for hyperthyroidism. International Journal of Cancer $1992 \mathbf{5 0} 886-890$.

23 Hoffman DA, McConahey WM, Fraumeni JF Jr \& Kurland LT. Cancer incidence following treatment of hyperthyroidism. International Journal of Epidemiology $198211218-224$.

24 Metso S, Jaatinen P, Huhtala H, Auvinen A, Oksala H \& Salmi J. Increased cardiovascular and cancer mortality after radioiodine treatment for hyperthyroidism. Journal of Clinical Endocrinology and Metabolism 200792 2190-2196.
25 John U, Greiner B, Hensel E, Lüdemann J, Piek M, Sauer S, Adam C, Born G, Alte D, Greiser E, Haertel U, Hense HW, Haerting J, Willich S \& Kessler C. Study of Health in Pomerania (SHIP): a health examination survey in an east German region: objectives and design. Sozial- und Präventivmedizin 200146 186-194.

26 Völzke H, Lüdemann J, Robinson DM, Spieker KW, Schwahn C, Kramer A, John U \& Meng W. The prevalence of undiagnosed thyroid disorders in a previously iodine-deficient area. Thyroid 200313 803-810.

27 Volzke H, Alte D, Kohlmann T, Ludemann J, Nauck M, John U \& Meng W. Reference intervals of serum thyroid function tests in a previously iodine-deficient area. Thyroid $200515279-285$.

28 Clauss A. Rapid physiological coagulation method in determination of fibrinogen. Acta Haematologica 195717 237-246.

29 von Elm E, Altman D, Egger M, Pocock S, Gøtzsche P \& Vandenbroucke J. STROBE initiative. The strengthening the reporting of observational studies in epidemiology (STROBE) statement: guidelines for reporting observational studies. Annals of Internal Medicine $2007 \mathbf{1 4 7} 573-577$.

30 Chubb SA, Davis WA \& Davis TM. Subclinical hypothyroidism and mortality in women with type 2 diabetes. Clinical Endocrinology $2006 \mathbf{6 4} 476-477$.

31 Knudsen N, Laurberg P, Perrild H, Bulow I, Ovesen L \& Jorgensen T. Risk factors for goiter and thyroid nodules. Thyroid 200212 879-888.

32 Völzke H, Schwahn C, Kohlmann T, Kramer A, Robinson DM, John U \& Meng W. Risk factors for goiter in a previously iodinedeficient region. Experimental and Clinical Endocrinology and Diabetes $2005113507-515$.

33 Kannel WB \& Higgins M. Smoking and hypertension as predictors of cardiovascular risk in population studies. Journal of Hypertension. Supplement 19908 S3-S8.

34 Stewart S, Hart CL, Hole DJ \& McMurray JJ. A population-based study of the long-term risks associated with atrial fibrillation: 20-year followup of the Renfrew/Paisley study. American Journal of Medicine 2002113 359-364.

35 Brabant G, Beck-Peccoz P, Jarzab B, Laurberg P, Orgiazzi J, Szabolcs I, Weetman AP \& Wiersinga WM. Is there a need to redefine the upper normal limit of TSH? European Journal of Endocrinology $2006154633-637$.

Received 8 December 2009

Accepted 9 December 2009 